\title{
Review \\ Scoring Systems for Clinical Colon Capsule Endoscopy-All You Need to Know
}

\author{
Trevor Tabone $^{1, * \mathbb{D}}$, Anastasios Koulaouzidis ${ }^{2}$ (D) and Pierre Ellul ${ }^{1}$ \\ 1 Gastroenterology Department, Mater Dei Hospital, MSD 2090 Msida, Malta; pierre.ellul@gov.mt \\ 2 Department of Social Medicine \& Public Health, Pomeranian Medical University, 70-204 Szczecin, Poland; \\ akoulaouzidis@hotmail.com \\ * Correspondence: trevor.tabone@gov.mt
}

Citation: Tabone, T.; Koulaouzidis,

A.; Ellul, P. Scoring Systems for

Clinical Colon Capsule EndoscopyAll You Need to Know. J. Clin. Med. 2021, 10, 2372. https://doi.org/ $10.3390 / \mathrm{jcm} 10112372$

Academic Editors: Sandro Ardizzone and Romain Coriat

Received: 4 April 2021

Accepted: 26 May 2021

Published: 28 May 2021

Publisher's Note: MDPI stays neutral with regard to jurisdictional claims in published maps and institutional affiliations.

Copyright: (C) 2021 by the authors. Licensee MDPI, Basel, Switzerland. This article is an open access article distributed under the terms and conditions of the Creative Commons Attribution (CC BY) license (https:// creativecommons.org/licenses/by/ $4.0 /)$.

\begin{abstract}
In the constantly developing era of minimal diagnostic invasiveness, the role of colon capsule endoscopy in colonic examination is being increasingly recognised, especially in the context of curtailed endoscopy services due to the COVID-19 pandemic. It is a safe diagnostic tool with low adverse event rates. As with other endoscopic modalities, various colon capsule endoscopy scores allow the standardisation of reporting and reproducibility. As bowel cleanliness affects CCE's diagnostic yield, a few operator-dependent scores (Leighton-Rex and CC-CLEAR scores) and a computer-dependent score (CAC score) have been developed to grade bowel cleanliness objectively. CCE can be used to monitor IBD mucosal disease activity through the UCEIS and the panenteric CECDAIic score for UC and CD, respectively. CCE may also have a role in CRC screening, given similar sensitivity and specificity rates to conventional colonoscopy to detect colonic polyps $\geq 10 \mathrm{~mm}$ and CRC. Given CCE's diagnostic yield and reproducible clinical scores with high inter-observer agreements, CCE is fast becoming a suitable alternative to conventional colonoscopy in specific patient populations.
\end{abstract}

Keywords: colon capsule endoscopy; colonoscopy; endoscopy score; inter-observer agreement; polyps; bowel preparation; inflammatory bowel disease; minimally invasive

\section{Introduction}

The disruption brought about by the 2019 novel coronavirus (COVID-19) pandemic has led to a forward push with genuine innovation to expand healthcare services. Adjusting to curtailed nonemergency endoscopy services has led to a renewed interest in alternative modalities for colonic exploration, in an attempt to mitigate potential diagnostic delays. One such strategy to visualize the colon is by means of colon capsule endoscopy (CCE), which allows for a pain-free colonic assessment by eliminating the need for instrument insertion, gas insufflation or sedation [1,2]. This has allowed for the extension of CCE's role in colorectal cancer (CRC) screening in the average-risk population, as well as an alternative for patients who refuse optical colonoscopy (OC) or in whom the latter is contraindicated [3-5]. Although CT colonography (CTC), like CCE, can visualise the colon without biopsy or therapy capabilities, in CTC, gas insufflation is required while concerns remain as to the "allowed" frequency of use due to radiation exposure.

In daily endoscopic practice, the use of various scores and scoring systems allow for the standardisation of reporting to increase objectivity, the reproducibility of findings and inter-observer agreement such as a description of lesions, mucosal disease activity and the adequacy of bowel preparation [6]. Eventually, the standardisation of reporting enables a higher quality of care and facilitates decision making and the continuity of care. Given the increasing use of CCE in clinical practice, we review the currently available scoring systems used in clinical CCE. 


\section{Bowel Cleanliness Scoring}

The Boston Bowel Preparation Scale (BBPS) is a visual scale in which conventional colonoscopy images are rated according to a quantitative grading based on the aggregate of separate scores obtained from the right, transverse and left colon, respectively [7]. Each colonic segment is given a score from 0 to 3 , with 0 denoting an unprepared colon segment in which the mucosa could not be visualised, due to solid stool which could not be cleared. A score of 1 denotes that a portion of the colonic mucosa could be seen; however, other areas were inadequately visualised because of residual stool, staining and/or opaque liquid. A score of 2 represents an adequately visualised colonic mucosa despite a minor residual staining, small stool fragments and/or opaque liquid. When the entire colonic mucosa within a segment is well visualised with no residual staining, small stool fragments or opaque liquid, a score of 3 is given. With an Intraclass Correlation Coefficient (ICC) of 0.91, the BBPS is regarded as having a significantly high inter-rater reliability. The BBPS also demonstrates that increasingly adequate mucosal visualisation is associated with improved polyp detection rates. BBPS segment scores of 2 and 3 versus 0 and 1 were correlated with higher polyp detection rates in the left colon (OR 2.58, 95\% CI 1.34-4.98) and right colon (OR 1.60, 95\% CI 1.01-2.55) [7].

Validated scores for OC cannot be used for CCE [8]. This is because scores such as the BBPS are typically applied during the withdrawal phase of OC after the endoscopist has attempted all cleaning manoeuvres, thus reflecting the actual practice of OC. Owing to the inherent inability to perform such manoeuvres during CCE, such scores cannot be translated to CCE. Van Gossum et al., in a multicentre study comparing CCE (Pillcam ${ }^{\circledR} \mathrm{COLON}-1$, Given Imaging Ltd, Yokneam, Israel) and OC, demonstrated an association between the cleanliness level and the accuracy of CCE for detecting polyps. In terms of CCE and detection of colorectal polyps and cancer, the sensitivity of CCE was significantly higher in patients with good or excellent colon cleanliness than in those with fair or poor colon cleanliness. The latter was determined using a four-point grading scale (Table 1), a global colonic assessment, as opposed to the segmental scoring approach present in the BBPS.

Table 1. Grading of bowel cleanliness.

\begin{tabular}{cr}
\hline Grade & Colon Cleanliness \\
\hline A & Large amount of faecal residue \\
\hline B & Enough faeces or dark fluid present to preclude a completely reliable examination \\
\hline C & Small amount of faeces or dark fluid, but not enough to interfere with examination \\
\hline D & No more than small bits of adherent faeces \\
\hline
\end{tabular}

In the detection of polyps $\geq 6 \mathrm{~mm}, \mathrm{CCE}$ demonstrated a specificity of $75 \%$ (95\% CI 65-83) in patients with good/excellent bowel cleanliness compared to $42 \%$ (95\% CI 28-56) in patients with fair/poor bowel cleanliness. Similarly, for advanced adenomas (defined as adenomas $\geq 10 \mathrm{~mm}$ or adenomas with villous features or high-grade dysplasia), an improved sensitivity of $88 \%$ (95\% CI 74-95) was noted in those with better bowel cleanliness as opposed to a sensitivity of $44 \%$ (95\% CI 25-64) for those with a poorer bowel cleanliness [9].

\subsection{Colon Capsule Bowel Cleansing Scores}

The diagnostic yield for CCE depends on two significant factors, including bowel preparation and image interpretation [10]. Similar to OC, CCE views allow for a detailed mucosal assessment. Figure 1 demonstrates a normal colonic mucosal appearance on CCE. Various pathologies apart from those mentioned in the scoring review can be detected, such as colonic angiodysplasias (Figure 2), internal haemorrhoids (Figure 3), and diverticula (Figure 4). 


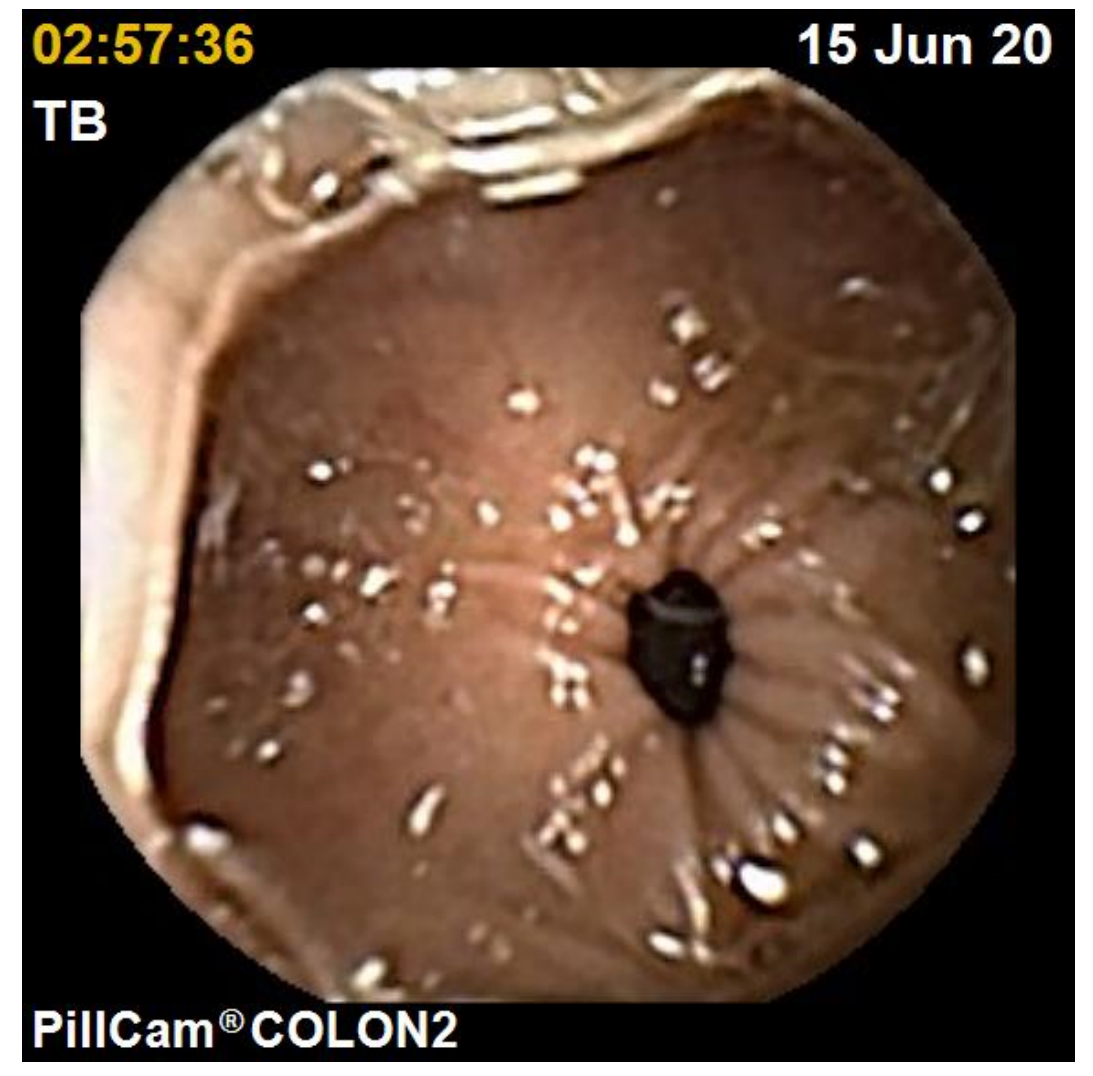

Figure 1. Normal colon.

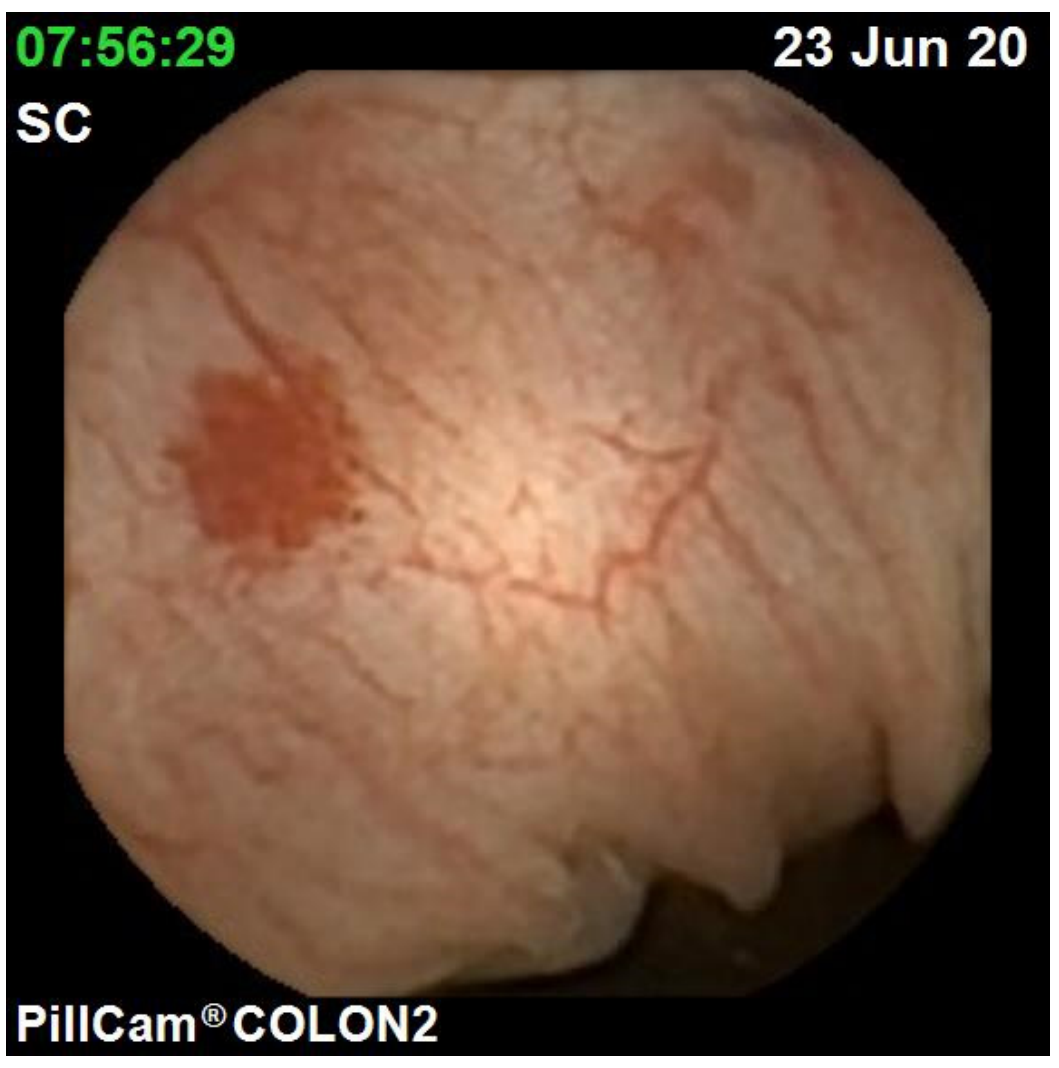

Figure 2. Colonic angiodysplasia. 


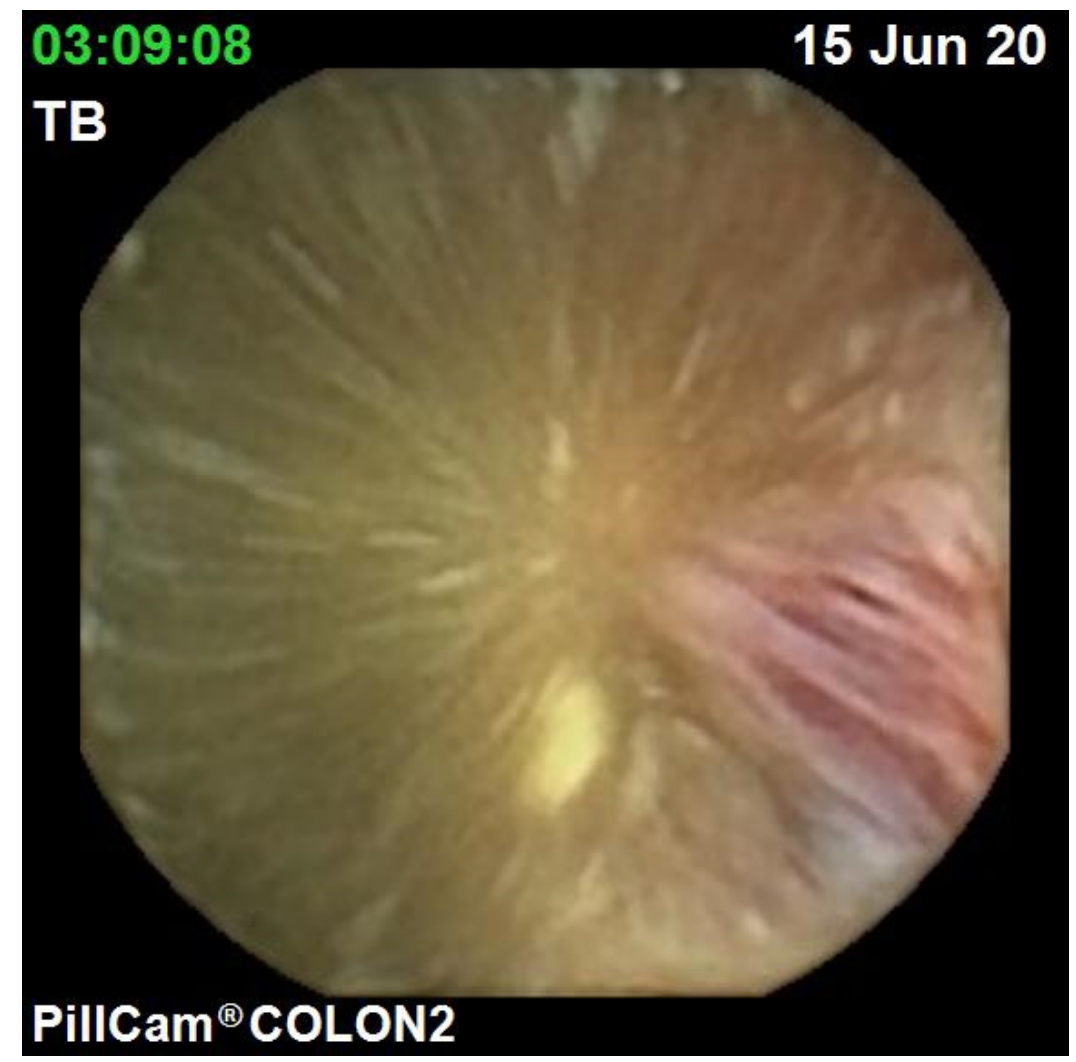

Figure 3. Haemorrhoid.

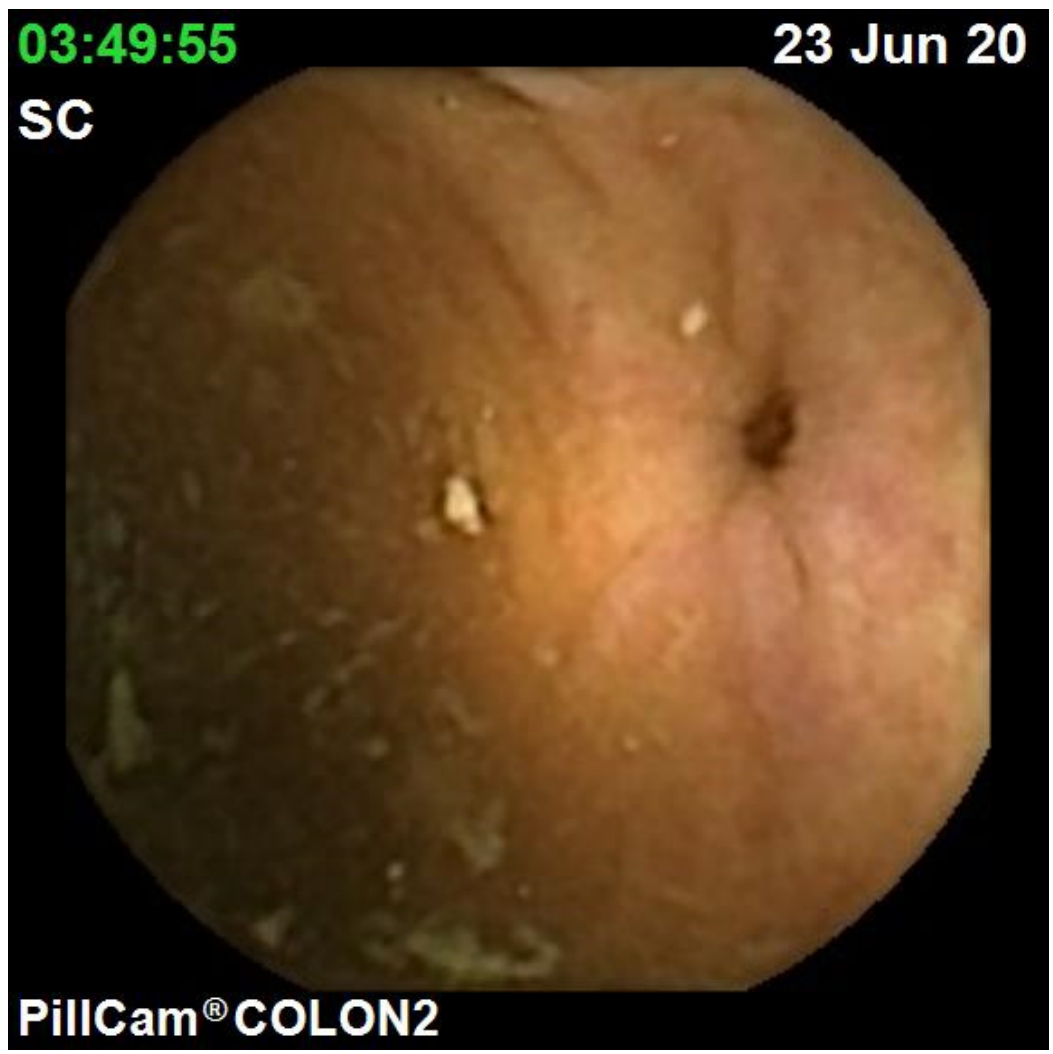

Figure 4. Colonic diverticulum. 
The bowel preparation regimen typically used in CCE involves large-volume (3-4 L) lavage with polyethylene glycol (PEG) in combination with prokinetics and boosters [10]. Whilst cleaning the colon, this regimen promotes capsule propulsion and creates a watery medium for the capsule to move. The relative complexity and duration of bowel preparation contrast with other noninvasive diagnostic modalities such as CTC. The latter can be performed with laxative-free regimes, which make exclusive use of faecal tagging solutions [11]. This is advantageous over the more aggressive bowel preparation regime required for $\mathrm{CCE}$ as it better tolerated by the elderly and a has more favourable side-effect profile in patients with renal or liver impairment $[12,13]$.

\subsubsection{Operator-Dependent Scores}

The Leighton-Rex scale is a qualitative scale that divides the colon into five segments (caecum, right colon, transverse, left colon and rectum). The five segments are graded individually with regard to overall cleansing level and bubbles grading (Table 2). This score analyses the entire video but is entirely subjective. This study recruited 40 patients, made use of the Pillcam ${ }^{\circledR}$ COLON-2 (Medtronic, Dublin, Ireland), and was not designed to validate the clinical utility of the tested scale [14].

Table 2. Leighton-Rex Scale.

\begin{tabular}{cr}
\hline \multicolumn{1}{c}{ Rating } & Description \\
\hline Cleansing Level Scale & Inadequate. Large amount of faecal residue precludes a complete examination \\
\hline Poor & Inadequate but examination completed. Enough faeces or turbid fluid to prevent a reliable examination \\
\hline Fair & Adequate. Small amount of faeces or turbid fluid not interfering with examination \\
\hline Good & Adequate. No more than small bits of adherent faeces \\
\hline Excellent & Bubbles that interfere with the examination. More than 10\% of surface area obscured by bubbles \\
\hline Bubbles Effect Scale & No bubbles or bubbles that do not interfere with the examination. Less than 10\% of surface area obscured \\
by bubbles
\end{tabular}

Another operator-dependent bowel cleansing score is the Colon Capsule CLEansing Assessment and Report (CC-CLEAR). This is a quantitative scale where, in the study, 58 patients were recruited. The study used Pillcam ${ }^{\circledR} \mathrm{COLON}-2$. In this score, the colon was divided into three segments: right, transverse and left colon. Each segment was scored according to an estimation of the percentage of visualized mucosa $(0:<50 \% ; 1: 50-75 \%$; 2: $>75 \% ; 3:>90 \%)$. The overall cleansing classification was a sum of each segment score, grading between excellent (8-9), good (6-7) and inadequate (0-5). Any segment scoring $\leq 1$ resulted in an inadequate overall classification. The colon videos were reviewed by two, blinded to each other, operators and were scored by the two available operator-dependent scores: CC-CLEAR and the Leighton-Rex score scale. The CC-CLEAR interobserver agreement was superior to the Leighton-Rex scale (Kendall's W 0.911 vs. $0.806, p<0.01$ ) [14].

One explanation for this might be due to the subjective clinical judgment on which the Leighton-Rex scale relies instead of the more objective, quantitative assessment of the percentage of visualized mucosa needed for CC-CLEAR. Moreover, the Leighton-Rex scale is more cumbersome to use in clinical practice as the colon needs to be divided into five different segments, which is a challenging task in practice, as well as the separate analysis of the "bubbles effect", which is likely unnecessary as they equally interfere with mucosal visualization together with faecal residue. Endoscopists might find the CC-CLEAR a more user-friendly score as the colon needs to be divided into just three segments: right colon, transverse and left colon, based on the hepatic and splenic flexure landmarks. 


\subsubsection{Computer-Dependent Scores}

An automated score, similar to that of Van Weyenberg et al. for the small bowel (SB), was developed: the colonic computed assessment of cleansing (CAC) score. This was based on a still frame colorimetric analysis of the tissue colour bar. The Pillcam ${ }^{\circledR}$ COLON-2 system was used. The CAC score, defined as the ratio of colour intensities, red over green ( $R / G$ ratio) and red over brown $(R /(R+G)$ ratio), was calculated for extracted colonic frames. A threshold was applied and, thus, one was able to discriminate "adequately cleansed" from "inadequately cleansed" CCE still frames. Though automated systems can apply a rapid and reproducible score, the current limitations, bubbles, luminosity and contrast, which contribute to clarity, are not considered. Furthermore, as opposed to an entire video, still frames were used, thus leading to a lot of unanalysed frames. However, such a score may circumvent the subjectivity of qualitative grading systems [15].

\section{Mucosal Disease Activity in Inflammatory Bowel Disease}

CCE is an effective tool to noninvasively assess mucosal disease activity in inflammatory bowel disease (IBD), enabling the monitoring of response to treatment, determine mucosal healing, and surveillance. With the introduction of higher-accuracy second-generation CCE (PillCam ${ }^{\circledR} \mathrm{COLON}-2$ ), the CCE's usefulness for the noninvasive assessment of mucosal disease activity is currently being explored [16].

\subsection{Ulcerative Colitis}

In 2018, Hosoe et al. aimed to develop an endoscopic severity score for ulcerative colitis (UC) using the PillCam ${ }^{\circledR}$ COLON-2 [17]. Patients diagnosed with UC were enrolled prospectively and underwent colonoscopy and CCE on the same day. The CSUC score was developed using the collected CCE videos, which four blinded IBD experts scored. The descriptors validated with the Ulcerative Colitis Endoscopic Index of Severity (UCEIS) were used as the candidate items, some of which were automatically assessed using the workstation.

The UCEIS descriptors used in the CSUC score including vascular pattern (graded as normal, patchy obliteration and obliterated), bleeding (graded as none, mucosal, luminal mild, and luminal moderate or severe) and erosions and ulcers (graded as none, small erosions $\leq 5 \mathrm{~mm}$, superficial ulcer $\geq 5 \mathrm{~mm}$, and deep ulcer) [18] are shown in Table 3 .

Table 3. CSUS descriptors and definitions.

\begin{tabular}{ccc}
\hline Descriptor & Likert Scale Anchor Points & Definition \\
\hline Vascular Pattern & Normal (0) & Normal vascular pattern \\
\hline & Patchy obliteration (1) & Obliterated area $\leq 30 \%$ \\
\hline Obliterated (2) & Obliterated area $>30 \%$ \\
\hline Bleeding & None (0) & No bleeding picture detected by image reading software $\leq 10$ \\
\hline Mrosions and ulcers & Severe (2) & No bleeding picture detected by image reading software $>10$ \\
\hline & None (0) & Normal mucosa, no visible erosions or ulcers \\
\hline & Erosions (1) & Tiny $(\leq 5$ mm) defects in the mucosa \\
\hline & Superficial ulcer (2) & Larger $(>5$ mm) defects in the mucosa \\
\hline & Deep ulcer (3) & Larger $(>5$ mm) and deeper excavated defects in the mucosa, with a \\
& slightly raised edge
\end{tabular}

Each of the validated UCEIS descriptors was divided into proximal and distal parts at the splenic flexure and then individually assessed. This was thought to express the inflammation severity more accurately than conventional scoring, which takes into account the point of maximum intensity. The visual analogue scale (VAS) was simultaneously used 
by the image readers to score the inflammation of the entire colon between 0 "completely normal" and 100 "worst ever seen".

In the meantime, the UCEIS of the proximal and distal parts was scored by two expert endoscopists using colonoscopy videos. This was considered as the gold standard.

The descriptors that contribute to the VAS were evaluated, and a model (estimating each item's weighting) to predict the VAS was constructed. Moreover, the score's contribution by colonic region (proximal, distal, or the sum of both) was accounted for. Through multiple regression analysis, the final scoring system was determined as "vascular pattern sum (proximal + distal) + bleeding sum + erosions and ulcers sum (minimum-maximum, 0-14)" and was named Capsule Scoring of Ulcerative Colitis (CSUC).

In terms of score validation, the authors showed an overall mean-weighted intraobserver agreement kappa value of 0.86 (95\% CI 0.69-1.00). The interobserver kappa value was $0.52(95 \%$ CI $0.45-0.59)$. This was low due to the lower dispersion of scores concerning bleeding. The proportion of agreement was, however, very high, with 0.96 (95\% CI 0.94-0.98) for proximal and 0.90 (95\% CI 0.87-0.93) for distal. The authors then compared the CSUC and UCEIS calculated from Pillcam ${ }^{\circledR} \mathrm{COLON}-2$ and OC videos, respectively. The correlation coefficients of these two endoscopic scores with a clinical activity score and faecal and blood biomarkers were calculated.

As a clinical score, the Lichtiger index was used. This score consists of eight clinical variables: number of bowel openings daily, nocturnal diarrhoea, percentage of visible blood in the stool, faecal incontinence, abdominal pain/cramping, general well-being, abdominal tenderness and need for anti-diarrhoeal agents. The score ranges from 0 to 21 points (remission is defined $\leq 3$, mild activity $4-8$, moderate $9-14$, and $\geq 15$ severe disease). The correlation coefficients of CSUC and UCEIS with the Lichtiger index were 0.60 and 0.48 , respectively (95\% CI 0.42-0.79).

In terms of blood biomarkers, the correlation coefficients of CSUC and UCEIS with WBC were found to be 0.40 and 0.33 (95\% CI 0.31-0.48), respectively, and for CRP, these were 0.20 and 0.13 (95\% CI 0.00-0.45), respectively.

A moderate association between CSUC and faecal calprotectin (FC) was present with a correlation coefficient of 0.46 (95\% CI 0.19-0.72), whilst the correlation between UCEIS and FC was found to be 0.50. In 2015, Theede et al. demonstrated that FC can be used as a surrogate for mucosal healing as it is strongly associated with clinical disease activity (Partial Mayo Score), histological disease activity and endoscopic disease activity (UCEIS) [19]. Given the comparable correlations between FC, UCEIS and CSUC, there is a potential role for the use of Pillcam ${ }^{\circledR} \mathrm{COLON}-2$ in assessing mucosal healing.

CSUC may also be used as a predictor for the risk of relapse during clinical remission. In a retrospective observational study by Matsubayashi et al., patients were more likely to maintain clinical remission for a year if they had a CSUC score of $\leq 1$ following 6 months of successful induction treatment. The calculated correlation coefficient for CSUC with FC was 0.50 (2-tailed $p$-value $<0.01)$ in this study. In addition, a CSUC $\geq 1$ was shown to be a predictor of relapse through receiver operator characteristic curve analysis (area under the curve of 0.82 , sensitivity of $83.3 \%$, and specificity of $58.6 \%$ ) [20].

Overall, the CSUC is a user-friendly score consisting of three simple parameters which can be easily generated using capsule endoscopy software; however, it will need further validation to determine whether Pillcam ${ }^{\circledR} \mathrm{COLON}-2$ can be used to accurately determine the UC inflammation extent [16].

\subsection{Crohn's Disease}

The usefulness of CCE in Crohn's disease (CD) remains unclear, contrasting with the established role of SB capsule endoscopy (SBCE) for the assessment of SB mucosal disease activity. In order to standardise the SB inflammatory burden in CD, two validated capsule endoscopy scores have been developed over the years, namely the Lewis score and the Capsule Endoscopy Crohn's Disease Activity Index (CECDAI or Niv score). The CECDAI 
evaluates three endoscopic parameters: inflammation severity, disease extent and presence of strictures.

With the current availability of Pillcam ${ }^{\circledR} \mathrm{COLON}-2$, which allows for the visualisation of colonic inflammatory disease activity, Niv et al. extended the validated CECDAI score to include the colon, introducing the novel CECDAIic score, allowing for an objective panenteric assessment of CD inflammatory activity (Table 4).

Table 4. CECDAIic score ${ }^{1}$.

\begin{tabular}{|c|c|}
\hline Parameter & \\
\hline A & Inflammation score \\
\hline 0 & None \\
\hline 1 & Mild to moderate oedema/hyperaemia/denudation \\
\hline 2 & Severe oedema/hyperaemia/denudation \\
\hline 3 & Bleeding, exudate, aphthous ulcer, erosion and small ulcers $(<0.5 \mathrm{~cm})$ \\
\hline 4 & Moderate ulcer $(0.5-2 \mathrm{~cm})$, pseudopolyp \\
\hline 5 & Large ulcer $(>2 \mathrm{~cm})$ \\
\hline B & Extent of disease score \\
\hline 0 & None \\
\hline 1 & Focal disease (single segment) \\
\hline 2 & Patchy disease (multiple segments) \\
\hline 3 & Diffuse disease \\
\hline $\mathrm{C}$ & Narrowing (stricture) \\
\hline 0 & None \\
\hline 1 & Single passed \\
\hline 2 & Multiple passed \\
\hline 3 & Obstruction \\
\hline
\end{tabular}

${ }^{1}$ Segmental score $=\mathrm{A} \times \mathrm{B}+\mathrm{C}$. Total score $=(\mathrm{A} 1 \times \mathrm{B} 1+\mathrm{C} 1)+(\mathrm{A} 2 \times \mathrm{B} 2+\mathrm{C} 2)+(\mathrm{A} 3 \times \mathrm{B} 3+\mathrm{C} 3)+(\mathrm{A} 4 \times \mathrm{B} 4+\mathrm{C} 4)$. (1) Proximal small bowel; (2) Distal small bowel; (3) Right colon; (4) Left colon.

A high level of inter-observant agreement was achieved for all parameters in the CECDAIic score, other than for strictures of the proximal small bowel and distal colon (C1 and C4). The panenteric Kendall coefficient was 0.77, whilst that for the small bowel was 0.85 [21].

This statistically significant high correlation was reproduced by Ariera et al. in a separate study, achieving a superior Kendall coefficient of 0.94 [22]. The authors also showed a high inter-observer concordance for all the subscores of CECDAIic (A1 $=0.91$; $\mathrm{B} 1=0.95 ; \mathrm{C} 1=1 ; \mathrm{A} 2=0.91 ; \mathrm{B} 2=0.91 ; \mathrm{C} 2=0.87 ; \mathrm{A} 3=0.84 ; \mathrm{B} 3=0.80 ; \mathrm{C} 3=1 ; \mathrm{A} 4=0.94 ;$ $\mathrm{B} 4=0.88 ; \mathrm{C} 4=1 ; p<0.001)$. However, as this was a retrospective study with a small number of patients, further validation with prospective studies with a larger number of patients is required.

Furthermore, this study examined the correlation between CECDAIic, FC and CRP, respectively (correlation coefficients 0.82 and 0.52 , respectively). Although a strong correlation between FC and CECDAIic was established, $66.7 \%(n=2)$ of the three patients with normal FC were still found to have significant inflammatory activity on panenteric capsule endoscopy (Pan-CE). This is in line with previous evidence that biomarker levels such as FC tend to correlate modestly with small bowel disease activity.

Several potential advantages to using Pan-CE over OC followed by SBCE include patient preference given the need for just one bowel preparation and fewer days off work with Pan-CE. Parodi et al. showed that out of 177 patients, $40.7 \%(n=72)$ would prefer 
capsule endoscopy over OC for future colorectal examinations-the latter was preferred in just $22.6 \%(n=40)$. The rest (36.7\%) expressed no preference in this study [23].

The comparison of findings on Pan-CE to OC and SBCE established a good correlation between Pan-CE and OC $(r=0.6667, p<0.035)$ and Pan-CE and SBCE $(r=0.896, p<0.0004)$ for colonic and SB disease activity, respectively [24].

The currently available data appear to support the use of Pan-CE and the CECDAIic score in order to objectively assess the inflammatory disease activity in SB and colonic $\mathrm{CD}$. The CECDAIic is reproducible, with a high degree of inter-observer agreement for the overall score and also for its individual sub-scores. In the current treat-to-target era, Pan-CE and CECDAlic use may be superior to biomarkers such as FC in establishing mucosal healing [22].

Pan-CE may also be a more cost-effective strategy over OC and imaging in the monitoring of CD. In a model study by Saunders et al., the calculated annual savings were USD 1135 per patient exclusively monitored with Pan-CE. The authors argue that this is likely due to the earlier recognition of active disease and timely initiation of treatment, thus offsetting the costs incurred with the need for inpatient care and surgery [25]. The potential cost-savings between the use of biomarkers such as FC and Pan-CE remain to be investigated.

\section{Polyp Detection and Size Estimation}

The role of identifying and removing adenomatous polyps during colonoscopy in the prevention of colorectal cancer is well-established. Poor adherence to OC by the screening population is an important limiting factor of screening colonoscopy due to its invasive nature and associated embarrassment. It also has a role in the detection or surveillance of colonic polyp(s) if the previous OC was incomplete or in the presence of severe medical co-morbidities where sedation would be deemed a high risk [26].

Various studies have demonstrated that CCE could visualize colonic segments missed by colonoscopy in $84.0-93.5 \%$ of patients [27-31].

However, one small retrospective pilot study did not demonstrate any role of CCE on incomplete OC [30].

The second-generation colon capsule, Pillcam ${ }^{\circledR} \mathrm{COLON}-2$, has demonstrated a much better performance in detecting colonic polyps. The integrated polyp size estimation tool within the RAPID software (Given ${ }^{\circledR}$ Imaging Ltd., Yokneam, Israel) when using Pillcam ${ }^{\circledR}$ COLON-2 allows the ease and reliability of measurement of polyp size in millimetres.

In a meta-analysis in 2016, comparing Pillcam ${ }^{\circledR}$ COLON-2 with OC, CCE detected polyps $>10 \mathrm{~mm}$ with $87 \%$ sensitivity ( $95 \% \mathrm{CI}, 81-91 \%$ ) and $95.3 \%$ specificity (95\% CI, 91.5-97.5\%) and identified all 11 invasive cancers detected by colonoscopy (100\% sensitivity/specificity) [32]. In addition, Hagel et al. compared Pillcam ${ }^{\circledR}$ COLON-2 with OC, using polyp-by-polyp findings with respect to location as defined by two highly experienced SB capsule endoscopists and specifically trained for CCE. The per-finding analysis for CCE polyp location estimation demonstrated sensitivity and specificity rates of $90.1 \%$ and $76.9 \%$, respectively [33].

An additional advantage to Pillcam ${ }^{\circledR} \mathrm{COLON}-2$ over its first-generation predecessor is the ability to differentiate between adenomatous polyps and hyperplastic polyps with a sensitivity of $91.2 \%$ and specificity of $88.2 \%$ [34]. This is possible through digital imaging processing technologies such as flexible spectral imaging colour enhancement (FICE) and blue mode (BM). Therefore, for those patients in whom a hyperplastic polyp is identified on CCE, OC might not be necessary.

One of the main competitors for CCE is CTC. In a study in patients with positive immunohistochemical faecal occult blood tests (iFOBTs) who underwent CCE (using Pillcam ${ }^{\circledR}$ COLON-2), CTC, and colonoscopy, CCE and CTC displayed identical performances in CRC screening. CCE identified $\geq 6 \mathrm{~mm}$ polyps, with an $88.2 \%$ sensitivity and $87.8 \%$ specificity, whereas CTC had an $88.2 \%$ sensitivity and $84.8 \%$ specificity [35]. In a 
more recent study, CCE (Pillcam ${ }^{\circledR}$ COLON-2) was superior to CTC for the detection of polyps $\geq 6 \mathrm{~mm}$ and noninferior for the identification of polyps $\geq 10 \mathrm{~mm}$ [36].

There has been an increased demand for the use of noninvasive screening tests for CRC given the scarce resources associated with the COVID-19 pandemic. Stool-based DNA testing is one such modality which, when compared to $O C$ as the reference standard in the DeeP-C cross-sectional study, was found to have sensitivity and specificity rates of $92.3 \%$ and $86.6 \%$, respectively, for detecting CRC. Despite CCE having a comparable CRC detection of $93 \%$, its potential drawback as a screening tool in CRC detection lies within the need for bowel preparation and variable completion rates [3,37].

\section{Discussion}

In an effort to still ensure timely diagnoses in the setting of curtailed nonemergency services as a result of the COVID-19 pandemic, the role of CCE as a safe, noninvasive method to investigate the colon is being increasingly recognised. CCE is being used in various aspects of endoscopic practice traditionally associated exclusively with OC such as CRC screening and mucosal disease activity assessment in IBD.

The use of OC as a CRC screening tool may be limited by the poor acceptance rate owing to patients' concerns regarding its invasive nature, perceived lack of privacy, and potential adverse effects, together with logistical and financial implications from workrelated absences [38]. CCE is an alternative investigation which could potentially mitigate such valid patient concerns, whilst still demonstrating comparable colonic polyp and CRC detection rates to $O C$ as discussed previously [32]. Therefore, using CCE as a screening test for CRC could improve patient acceptance rates, whilst possibly reserving OC for therapeutic purposes. According to the European Society of Gastrointestinal Endoscopy (ESGE), CCE can be used in average-risk patients for CRC screening and as an adjunctive test in patients with a prior incomplete OC, or in whom the latter is contraindicated or refused [39].

Considering that the current estimated rate of incomplete OC is 1-43\%, CCE lends itself as an important alternative to visualize the colonic mucosa in its entirety [40]. In a prospective study including 75 patients, CCE was able to progress beyond the colonic segment at which OC stopped in $91 \%$ of patients with a prior history of incomplete OC [30]. This resulted in the diagnosis of additional significant findings in $36 \%$ of sameday cases and in $48 \%$ of rescheduled ones. Moreover, a prospective, comparative trial between CCE and CTC in patients with incomplete OC demonstrated a relative sensitivity of CCE compared to CTC of 2.0 (95\% CI 1.34 to 2.98) for polyps $\geq 6 \mathrm{~mm}$. For larger polyps $\geq 10 \mathrm{~mm}$, the relative sensitivity of CCE over CTC was 1.67 (95\% CI 0.69-4.00). Positive predictive values for polyps $\geq 6$ and $\geq 10 \mathrm{~mm}$ were $96 \%$ and $85.7 \%$, and $83.3 \%$ and $100 \%$ for CCE and CTC, respectively [41]. In this study, both CCE and CTC achieved complete colonic evaluation in $98 \%$ of cases. This would suggest that CCE is a potentially more suitable investigation after an incomplete $\mathrm{OC}$ given its superior diagnostic yield over CTC [42].

Beyond the realm of incomplete OC, CCE is also suitable for patients considered too high-risk for OC or unwilling to undergo OC. From a prospective study of 70 high-risk patients who had refused or were unable to undergo OC, CCE revealed significant findings in $34 \%$ of patients [43].

In terms of cost-effectiveness, a computer model based on a Markov process in a hypothetical population of 100,000 individuals aged 50 and over undergoing a 10-yearly screening procedure demonstrated an incremental cost-effectiveness (compared with no screening) of OC and CCE of USD 16,165 and USD 29,244 per life-year saved, respectively. This showed that the OC program was less costly and more effective than CCE. The authors, however, showed that if the initial compliance to CCE were to be $30 \%$ better than OC, then CCE becomes the more cost-effective option [44].

The choice between CCE, OC and CTC can be challenging in everyday practice. The decision relies on several different factors such as patient consent, fitness for sedation, 
ability to tolerate bowel preparation, acceptable exposure to ionizing radiation, the need to assess for extra-colonic pathology, and also the availability and expertise for each and every modality. Table 5 summarizes pertinent variables to consider before choosing a suitable modality for a particular patient.

Table 5. Comparison between CCE, OC and CTC.

\begin{tabular}{|c|c|c|c|}
\hline & CCE & Diagnostic OC & CTC \\
\hline Bowel preparation & PEG + booster + prokinetic & PEG & $\begin{array}{l}\text { Laxative-free regimens using } \\
\text { faecal tagging solution [11] }\end{array}$ \\
\hline Ionising radiation exposure & None & None & $\leq 3-6 \mathrm{mSv}[45]$ \\
\hline Need for sedation & None & Yes & None \\
\hline $\begin{array}{l}\text { Suitability in high-risk } \\
\text { patients }\end{array}$ & $\begin{array}{l}\text { Potentially unsuitable given } \\
\text { relative aggressiveness of } \\
\text { bowel preparation }\end{array}$ & $\begin{array}{l}\text { Potentially unsuitable given } \\
\text { sedation-related risks }\end{array}$ & $\begin{array}{l}\text { Suitable owing to better } \\
\text { tolerated bowel preparation } \\
\text { and no need for sedation }\end{array}$ \\
\hline Bowel insufflation & None & Yes & Yes \\
\hline Extra-colonic findings & None & None & Yes \\
\hline $\begin{array}{c}\text { Detection of polyps } \geq 6 \mathrm{~mm} \\
\text { (sensitivity, specificity, } \\
\text { respectively) }\end{array}$ & $88.2 \%, 87.8 \%[35]$ & 'Gold standard' & $88.2 \%, 87.8 \%[35]$ \\
\hline Average cost & USD 950 [46] & USD 877 [44] & USD 500 [42] \\
\hline
\end{tabular}

The various CCE scores discussed earlier are summarized in Tables 6 and 7. These ensure good clinical practice, which can be audited as these allow for the standardisation of reporting between physicians, increase objectivity and enable continuity of care. The availability of these scores further supports the clinical use of CCE beyond CRC screening, but also in disease activity monitoring in IBD.

Table 6. Summary of bowel cleanliness scores.

\begin{tabular}{lcccc}
\hline Type of Computation & Name of Score & $\begin{array}{c}\text { Quantitative vs. } \\
\text { Qualitative }\end{array}$ & $\begin{array}{c}\text { Colonic Segmental } \\
\text { Division }\end{array}$ & Interobserver Agreement \\
\hline Operator-Dependant & Leighton-Rex & Qualitative & $\begin{array}{c}5 \text { segments: caecum, right } \\
\text { colon, transverse, left colon, } \\
\text { and rectum }\end{array}$ & Kendall's coefficient: 0.806 [14] \\
\hline Computer-Dependant & CAC & Qualitative & $\begin{array}{c}\text { 3 segments: right colon, } \\
\text { transverse, and left colon }\end{array}$ & Kendall's coefficient: 0.911 [14] \\
\hline
\end{tabular}

Table 7. Summary of CCE scores used in IBD.

\begin{tabular}{|c|c|c|c|c|c|c|}
\hline $\begin{array}{l}\text { Type of } \\
\text { IBD }\end{array}$ & $\begin{array}{l}\text { Name of } \\
\text { Score }\end{array}$ & $\begin{array}{l}\text { Quantitative } \\
\text { vs. Qualitative }\end{array}$ & $\begin{array}{l}\text { Parameters of Intestinal } \\
\text { Pathology Used }\end{array}$ & $\begin{array}{l}\text { Bowel Segmental } \\
\text { Division }\end{array}$ & Scoring Formula & $\begin{array}{c}\text { Interobserver } \\
\text { Agreement }\end{array}$ \\
\hline UC & CSUC & Quantitative & $\begin{array}{l}\text { Uses UCEIS descriptors: } \\
\text { Vascular pattern; } \\
\text { Bleeding; } \\
\text { Erosions and ulcer. }\end{array}$ & $\begin{array}{l}\text { Proximal colon; Distal } \\
\text { colon (divided at the } \\
\text { splenic flexure) }\end{array}$ & $\begin{array}{l}\text { Vascular pattern } \\
\text { sum (proximal + } \\
\text { distal) + bleeding } \\
\text { sum + erosions } \\
\text { and ulcers sum }\end{array}$ & $\begin{array}{c}\text { Mean-weighted } \\
\text { kappa value: } 0.52 \\
(95 \% \text { CI } 0.45-0.59) \\
{[17]}\end{array}$ \\
\hline $\mathrm{CD}$ & CECDAIic & Quantitative & $\begin{array}{c}\text { Inflammation (A); } \\
\text { Extent of disease (B); } \\
\text { Presence of strictures (C) }\end{array}$ & $\begin{array}{l}\text { Proximal small bowel } \\
\text { (1); Distal small bowel } \\
\text { (2); Right colon (3); } \\
\text { Left colon (4) }\end{array}$ & $\begin{array}{c}\text { Total score }=(\mathrm{A} 1 \\
\times \mathrm{B} 1+\mathrm{C} 1)+(\mathrm{A} 2 \\
\times \mathrm{B} 2+\mathrm{C} 2)+(\mathrm{A} 3 \\
\times \mathrm{B} 3+\mathrm{C} 3)+(\mathrm{A} 4 \\
\times \mathrm{B} 4+\mathrm{C} 4)\end{array}$ & $\begin{array}{c}\text { Kendall coefficient: } \\
0.77 \text { [21] }\end{array}$ \\
\hline
\end{tabular}




\section{Conclusions}

CCE is emerging as a safe, noninvasive and relatively painless procedure. In a recent meta-analysis, the pooled adverse event rate for capsule retention was $0.26 \%(95 \% \mathrm{CI}$ $0.00-0.77)$, whilst the procedural discomfort rate was $0.81 \%$ (95\% CI $0.15-1.80)$. The authors also demonstrated that the CCE technical failure rate was 1.76\% (95\% CI 0.76-3.06) [47]. This was defined as equipment malfunction, recording gaps, short battery life duration, activation failure and inability to download images.

Colonic incomplete examination, defined as CCE not excreted or not reaching the rectum within the recording time, was $19.19 \%$ (95\% CI 14.06-25.88) [47].

Its application as a safe diagnostic tool, associated with comparable sensitivity and specificity rates to OC for the detection of colonic polyps, as well as its role in assessing mucosal disease activity in IBD, makes the second-generation CCE a suitable diagnostic endoscopic modality alternative to OC.

CCE is, therefore, a potentially beneficial method of investigating patients by reducing the burden on the reinstatement of curtailed endoscopy services in the post-COVID era. Nevertheless, with the average completion time for OC being 30-60 min, CCE is potentially more cumbersome considering the transit time and subsequent dedicated reading time averaging 25-65 min depending on reader experience [48].

Author Contributions: Writing-original draft preparation, T.T.; writing-review and editing, P.E. and A.K.; supervision, P.E. All authors have read and agreed to the published version of the manuscript.

Funding: This research received no external funding.

Institutional Review Board Statement: Not applicable.

Informed Consent Statement: Not applicable.

Conflicts of Interest: The authors declare no conflict of interest.

\section{References}

1. Spada, C.; Hassan, C.; Bellini, D.; Burling, D.; Cappello, G.; Carretero, C.; Dekker, E.; Eliakim, R.; De Haan, M.; Kaminski, M.F.; et al. Imaging alternatives to colonoscopy: CT colonography and colon capsule. European Society of Gastrointestinal Endoscopy (ESGE) and European Society of Gastrointestinal and Abdominal Radiology (ESGAR) Guideline-Update 2020. Endoscopy 2020, 52, 1127-1141. [CrossRef] [PubMed]

2. NHS England NHS Rolls out Capsule Cameras to Test for Cancer. Available online: https://www.england.nhs.uk/2021/03/nhsrolls-out-capsule-cameras-to-test-for-cancer/ (accessed on 21 March 2021).

3. Vuik, F.E.R.; Nieuwenburg, S.A.V.; Moen, S.; Spada, C.; Senore, C.; Hassan, C.; Pennazio, M.; Rondonotti, E.; Pecere, S.; Kuipers, E.J.; et al. Colon capsule endoscopy in colorectal cancer screening: A systematic review. Endoscopy 2021. [CrossRef]

4. Kjølhede, T.; Ølholm, A.M.; Kaalby, L.; Kidholm, K.; Qvist, N.; Baatrup, G. Diagnostic accuracy of capsule endoscopy compared with colonoscopy for polyp detection: Systematic review and meta-analyses. Endoscopy 2020. [CrossRef] [PubMed]

5. Deding, U.; Kaalby, L.; Bøggild, H.; Plantener, E.; Wollesen, M.K.; Kobaek-Larsen, M.; Hansen, S.J.; Baatrup, G. Colon Capsule Endoscopy vs. CT Colonography Following Incomplete Colonoscopy: A Systematic Review with Meta-Analysis. Cancers 2020, 12, 3367. [CrossRef]

6. Limdi, J.K.; Picco, M.; Farraye, F.A. A review of endoscopic scoring systems and their importance in a treat-to-target approach in inflammatory bowel disease (with videos). Gastrointest. Endosc. 2020, 91, 733-745. [CrossRef]

7. Calderwood, A.H.; Jacobson, B.C. Comprehensive validation of the Boston Bowel Preparation Scale. Gastrointest. Endosc. 2010, 72, 686-692. [CrossRef]

8. Lai, E.J.; Calderwood, A.H.; Doros, G.; Fix, O.K.; Jacobson, B.C. The Boston bowel preparation scale: A valid and reliable instrument for colonoscopy-oriented research. Gastrointest. Endosc. 2009, 69, 620-625. [CrossRef]

9. Van Gossum, A.; Munoz-Navas, M.; Fernandez-Urien, I.; Carretero, C.; Gay, G.; Delvaux, M.; Lapalus, M.G.; Ponchon, T.; Neuhaus, H.; Philipper, M.; et al. Capsule Endoscopy versus Colonoscopy for the Detection of Polyps and Cancer. N. Engl. J. Med. 2009, 361, 264-270. [CrossRef]

10. Singhal, S.; Nigar, S.; Paleti, V.; Lane, D.; Duddempudi, S. Bowel preparation regimens for colon capsule endoscopy: A review. Ther. Adv. Gastroenterol. 2014, 7, 115-122. [CrossRef]

11. Neri, E.; Halligan, S.; Hellström, M.; Lefere, P.; Mang, T.; Regge, D.; Stoker, J.; Taylor, S.; Laghi, A. The second ESGAR consensus statement on CT colonography. Eur. Radiol. 2013, 23, 720-729. [CrossRef] 
12. Ojidu, H.; Palmer, H.; Lewandowski, J.; Hampton, J.; Blakeborough, T.; Epstein, O.; McAlindon, M.E. Patient tolerance and acceptance of different colonic imaging modalities. Eur. J. Gastroenterol. Hepatol. 2018, 30, 520-525. [CrossRef]

13. Woodbridge, L.; Wylie, P. Current Issues in Computed Tomography Colonography. Semin. Ultrasound CT MRI 2016, 37, 331-338. [CrossRef]

14. Magalhães, R.D.S.; Arieira, C.; Carvalho, P.B.; Rosa, B.; Moreira, M.J.; Cotter, J. Colon Capsule CLEansing Assessment and Report (CC-CLEAR): A new approach for evaluation of the quality of bowel preparation in capsule colonoscopy. Gastrointest. Endosc. 2021, 93, 212-223. [CrossRef]

15. Becq, A.; Histace, A.; Camus, M.; Nion-Larmurier, I.; Ali, E.A.; Pietri, O.; Romain, O.; Chaput, U.; Li, C.; Marteau, P.; et al. Development of a computed cleansing score to assess quality of bowel preparation in colon capsule endoscopy. Endosc. Int. Open 2018, 6, E844-E850. [CrossRef]

16. Hosoe, N.; Hayashi, Y.; Ogata, H. Colon Capsule Endoscopy for Inflammatory Bowel Disease. Clin. Endosc. 2020, 53, 550-554. [CrossRef]

17. Hosoe, N.; Nakano, M.; Takeuchi, K.; Endo, Y.; Matsuoka, K.; Abe, T.; Omori, T.; Hayashida, M.; Kobayashi, T.; Yoshida, A.; et al. Establishment of a Novel Scoring System for Colon Capsule Endoscopy to Assess the Severity of Ulcerative Colitis-Capsule Scoring of Ulcerative Colitis. Inflamm. Bowel Dis. 2018, 24, 2641-2647. [CrossRef]

18. Travis, S.P.L.; Schnell, D.; Krzeski, P.; Abreu, M.T.; Altman, D.G.; Colombel, J.-F.; Feagan, B.G.; Hanauer, S.B.; Lémann, M.; Lichtenstein, G.R.; et al. Developing an instrument to assess the endoscopic severity of ulcerative colitis: The Ulcerative Colitis Endoscopic Index of Severity (UCEIS). Gut 2011, 61, 535-542. [CrossRef]

19. Theede, K.; Holck, S.; Ibsen, P.; Ladelund, S.; Nordgaard-Lassen, I.; Nielsen, A.M. Level of Fecal Calprotectin Correlates With Endoscopic and Histologic Inflammation and Identifies Patients With Mucosal Healing in Ulcerative Colitis. Clin. Gastroenterol. Hepatol. 2015, 13, 1929-1936. [CrossRef]

20. Matsubayashi, M.; Kobayashi, T.; Okabayashi, S.; Nakano, M.; Sagami, S.; Ozaki, R.; Kiyohara, H.; Morikubo, H.; Asonuma, K.; Miyatani, Y.; et al. Determining the usefulness of Capsule Scoring of Ulcerative Colitis in predicting relapse of inactive ulcerative colitis. J. Gastroenterol. Hepatol. 2021, 36, 943-950. [CrossRef]

21. Niv, Y.; Gal, E.; Gabovitz, V.; Hershkovitz, M.; Lichtenstein, L.; Avni, I. Capsule Endoscopy Crohn's Disease Activity Index (CECDAIic or Niv Score) for the Small Bowel and Colon. J. Clin. Gastroenterol. 2018, 52, 45-49. [CrossRef]

22. Arieira, C.; Magalhães, R.; De Castro, F.D.; Carvalho, P.B.; Rosa, B.; Moreira, M.J.; Cotter, J. CECDAIic-A new useful tool in pan-intestinal evaluation of Crohn's disease patients in the era of mucosal healing. Scand. J. Gastroenterol. 2019, 54, 1326-1330. [CrossRef] [PubMed]

23. Parodi, A.; Vanbiervliet, G.; Hassan, C.; Hebuterne, X.; De Ceglie, A.; Filiberti, R.A.; Spada, C.; Conio, M. Colon capsule endoscopy to screen for colorectal neoplasia in those with family histories of colorectal cancer. Gastrointest. Endosc. 2018, 87, 695-704. [CrossRef] [PubMed]

24. Hall, B.; Holleran, G.; McNamara, D. PillCam COLON 2@ as a pan-enteroscopic test in Crohn's disease. World J. Gastrointest. Endosc. 2015, 7, 1230-1232. [CrossRef] [PubMed]

25. Saunders, R.; Torres, R.T.; Konsinski, L.; Kosinski, L. Evaluating the clinical and economic consequences of using video capsule endoscopy to monitor Crohn's disease. Clin. Exp. Gastroenterol. 2019, 12, 375-384. [CrossRef]

26. Ontario, H.Q. Colon capsule endoscopy for the detection of colorectal polyps: An evidence-based analysis. Ont. Health Technol. Assess. Ser. 2015, 15, 1-39. Available online: http:/ /www.hqontario.ca/evidence/evidence-process/evidence-review-process/ professional-and-public (accessed on 16 March 2021).

27. Hussey, M.; Holleran, G.; Stack, R.; Moran, N.; Tersaruolo, C.; McNamara, D. Same-day colon capsule endoscopy is a viable means to assess unexplored colonic segments after incomplete colonoscopy in selected patients. United Eur. Gastroenterol. J. 2018, 6, 1556-1562. [CrossRef]

28. Baltes, P.; Bota, M.; Albert, J.; Philipper, M.; Hörster, H.-G.; Hagenmüller, F.; Steinbrück, I.; Jakobs, R.; Bechtler, M.; Hartmann, D.; et al. PillCamColon2 after incomplete colonoscopy-A prospective multicenter study. World J. Gastroenterol. 2018, 24, 3556-3566. [CrossRef]

29. Nogales, Ó.; García-Lledó, J.; Luján, M.; Nicolás, D.; Juanmartiñena, J.F.; González-Suárez, B.; Ceballos, F.S.; Couto, I.; Olmedo, J.; Garfia, C.; et al. Therapeutic impact of colon capsule endoscopy with PillCam? COLON 2 after incomplete standard colonoscopy: A Spanish multicenter study. Rev. Española Enferm. Dig. 2017, 109, 322-327. [CrossRef]

30. Triantafyllou, K.; Viazis, N.; Tsibouris, P.; Zacharakis, G.; Kalantzis, C.; Karamanolis, D.G.; Ladas, S.D. Colon capsule endoscopy is feasible to perform after incomplete colonoscopy and guides further workup in clinical practice. Gastrointest. Endosc. 2014, 79, 307-316. [CrossRef]

31. Alarcón-Fernández, O.; Ramos, L.; Adrián-De-Ganzo, Z.; Gimeno-García, A.Z.; Nicolás-Pérez, D.; Jiménez, A.; Quintero, E. Effects of Colon Capsule Endoscopy on Medical Decision Making in Patients With Incomplete Colonoscopies. Clin. Gastroenterol. Hepatol. 2013, 11, 534-540. [CrossRef]

32. Spada, C.; Pasha, S.F.; Gross, S.A.; Leighton, J.A.; Schnoll-Sussman, F.; Correale, L.; Suárez, B.G.; Costamagna, G.; Hassan, C. Accuracy of First-and Second-Generation Colon Capsules in Endoscopic Detection of Colorectal Polyps: A Systematic Review and Meta-analysis. Clin. Gastroenterol. Hepatol. 2016, 14, 1533-1543. [CrossRef] 
33. Hagel, A.F.; Gäbele, E.; Raithel, M.; Hagel, W.H.; Albrecht, H.; de Rossi, T.M.; Singer, C.; Schneider, T.; Neurath, M.F.; Farnbacher, M.J. Colon Capsule Endoscopy: Detection of Colonic Polyps Compared with Conventional Colonoscopy and Visualization of Extracolonic Pathologies. Can. J. Gastroenterol. Hepatol. 2014, 28, 77-82. [CrossRef]

34. Nakazawa, K.; Nouda, S.; Kakimoto, K.; Kinoshita, N.; Tanaka, Y.; Tawa, H.; Koshiba, R.; Naka, Y.; Hirata, Y.; Ota, K.; et al. The Differential Diagnosis of Colorectal Polyps Using Colon Capsule Endoscopy. Intern. Med. 2021, 6446-20. [CrossRef]

35. Rondonotti, E.; Borghi, C.; Mandelli, G.; Radaelli, F.; Paggi, S.; Amato, A.; Imperiali, G.; Terreni, N.; Lenoci, N.; Terruzzi, V.; et al. Accuracy of Capsule Colonoscopy and Computed Tomographic Colonography in Individuals With Positive Results From the Fecal Occult Blood Test. Clin. Gastroenterol. Hepatol. 2014, 12, 1303-1310. [CrossRef]

36. Cash, B.D.; Fleisher, M.R.; Fern, S.; Rajan, E.; Haithcock, R.; Kastenberg, D.M.; Pound, D.; Papageorgiou, N.P.; Fernández-Urién, I.; Schmelkin, I.J.; et al. Multicentre, prospective, randomised study comparing the diagnostic yield of colon capsule endoscopy versus CT colonography in a screening population (the TOPAZ study). Gut 2020. [CrossRef]

37. Dockter, A.G.; Angelos, G.C. Stool-based DNA testing versus colon capsule endoscopy for colorectal cancer screening during the COVID-19 pandemic: A response to 'Colon capsule endoscopy: An innovative method for detecting colorectal pathology during the COVID-19 pandemic? Color. Dis. 2020, 22, 1027-1028. [CrossRef]

38. Pasha, S.F. Applications of Colon Capsule Endoscopy. Curr. Gastroenterol. Rep. 2018, 20, 22. [CrossRef]

39. Spada, C.; Hassan, C.; Galmiche, J.-P.; Neuhaus, H.; Dumonceau, J.-M.; Adler, S.N.; Epstein, O.; Gay, G.; Pennazio, M.; Rex, D.K.; et al. Colon capsule endoscopy: European Society of Gastrointestinal Endoscopy (ESGE) Guideline. Endoscopy 2012, 44, 527-536. [CrossRef]

40. Villa, N.A.; Pannala, R.; Pasha, S.F.; Leighton, J.A. Alternatives to Incomplete Colonoscopy. Curr. Gastroenterol. Rep. $2015,17$. [CrossRef]

41. Spada, C.; Hassan, C.; Barbaro, B.; Iafrate, F.; Cesaro, P.; Petruzziello, L.; Grazioli, L.M.; Senore, C.; Brizi, M.G.; Costamagna, I.; et al. Colon capsule versus CT colonography in patients with incomplete colonoscopy: A prospective, comparative trial. Gut 2014, 64, 272-281. [CrossRef]

42. Milluzzo, S.M.; Bizzotto, A.; Cesaro, P.; Spada, C. Colon capsule endoscopy and its effectiveness in the diagnosis and management of colorectal neoplastic lesions. Expert Rev. Anticancer. Ther. 2018, 19, 71-80. [CrossRef] [PubMed]

43. Negreanu, L.; Babiuc, R.; Bengus, A.; Sadagurschi, R. PillCam Colon 2 capsule in patients unable or unwilling to undergo colonoscopy. World J. Gastrointest. Endosc. 2013, 5, 559-567. [CrossRef] [PubMed]

44. Hassan, C.; Zullo, A.; Winn, S.; Morini, S. Cost-effectiveness of capsule endoscopy in screening for colorectal cancer. Endoscopy 2008, 40, 414-421. [CrossRef] [PubMed]

45. Yee, J.; McFarland, E. Extracolonic findings and radiation at CT colonography: What the referring provider needs to know. Abdom. Radiol. 2018, 43, 554-565. [CrossRef]

46. Muguruma, N.; Tanaka, K.; Teramae, S.; Takayama, T. Colon capsule endoscopy: Toward the future. Clin. J. Gastroenterol. 2017, 10, 1-6. [CrossRef]

47. Wang, Y.-C.; Pan, J.; Liu, Y.-W.; Sun, F.-Y.; Qian, Y.-Y.; Jiang, X.; Zou, W.-B.; Xia, J.; Jiang, B.; Ru, N.; et al. Adverse events of video capsule endoscopy over the past two decades: A systematic review and proportion meta-analysis. BMC Gastroenterol. 2020, 20, 1-11. [CrossRef]

48. Koulaouzidis, A.; Dabos, K.; Philipper, M.; Toth, E.; Keuchel, M. How should we do colon capsule endoscopy reading: A practical guide. Ther. Adv. Gastrointest. Endosc. 2021, 14, 263177452110019. [CrossRef] 